\title{
Serum urate and the risk of major coronary heart disease events
}

\author{
S Goya Wannamethee, A Gerald Shaper, Peter H Whincup
}

\begin{abstract}
Objective-To examine the relation between serum urate and the risk of major coronary heart disease events.

Design-A prospective study of a male cohort.

Setting-One general practice in each of 24 British towns.
\end{abstract}

Subjects-7688 men aged $40-59$ years at screening.

Main outcome measures-Fatal and nonfatal coronary heart disease events.

Results-There were 1085 major coronary heart disease events during the average follow up period of 16.8 years. Serum urate was significantly associated with a wide range of cardiovascular risk factors including body mass index, alcohol intake, antihypertensive treatment, preexisting coronary heart disease, serum triglycerides, cholesterol, and diastolic blood pressure. There was a significant positive association between serum urate and risk of coronary heart disease after adjustment for lifestyle factors and disease indicators. This relation was attenuated to non-significance upon additional adjustment for diastolic blood pressure and serum total cholesterol: cholesterol appeared to be the critical factor in attenuating this relation. When the association between serum urate and risk of coronary heart disease was examined by presence and grade of pre-existing coronary heart disease, a positive association was seen only in men with previous definite myocardial infarction, even after full adjustment (P $=0.07)$.

Conclusions-The relation between serum urate and the risk of coronary heart disease depends heavily upon the presence of pre-existing myocardial infarction and widespread underlying atherosclerosis as well as the clustering of risk factors. Thus serum urate is not a truly independent risk factor for coronary heart disease. Raised serum urate appears to be an integral part of the cluster of risk factors associated with the insulin resistance syndrome that include obesity, raised serum triglycerides, and serum cholesterol.

(Heart 1997;78:147-153)

Keywords: serum urate; coronary heart disease; risk factors
Raised serum urate concentrations have been associated with increased risk of coronary heart disease events. ${ }^{1-3}$ However, hyperuricaemia has also been shown to be associated with many cardiovascular risk factors, in particular raised blood pressure, pre-existing ischaemic heart disease, hyperlipidaemia, and the use of antihypertensive treatment..$^{3-9}$ Thus the role of serum urate in the development of coronary heart disease remains uncertain. There is increasing evidence that the relation between hyperuricaemia and the risk of coronary heart disease in men is dependent on the association between urate and other cardiovascular risk factors..$^{2-4-8}$ However, it is uncertain whether the observed relation is related to raised blood pressure or to the presence of established coronary heart disease. Hyperuricaemia is commonly found in people with coronary heart disease and although several studies have either excluded or adjusted for pre-existing coronary heart disease in multivariate analysis, few studies have examined the role of urate separately in the presence or absence of coronary heart disease. In those that have done so, the findings have been inconsistent. ${ }^{47}$ We have therefore examined the relation between serum urate and subsequent risk of coronary heart disease in a prospective study of over 7000 middle aged men followed up for an average of $16 \cdot 8$ years. This paper focuses on the role of other cardiovascular risk factors in the relation between urate and risk of coronary heart disease and on the role of urate as a predictor of coronary heart disease events in men with and without the presence of pre-existing coronary heart disease.

\section{Methods}

The British Regional Heart Study is a large prospective study of cardiovascular disease in 7735 men aged 40-59 years selected from the age/sex registers of one group general practice in each of 24 towns in England, Wales, and Scotland ( $78 \%$ response rate). The criteria for selecting the town, the general practice, and the subjects, as well as the methods of data collection, have been reported ${ }^{10}$ Research nurses administered a standard questionnaire to each man, which included questions on smoking habits, alcohol intake, physical activity, and medical history. Several physical measurements were made, and blood samples (non-fasting) were taken throughout the day between 0830 and 1830 . Thirteen biochemical measurements, including serum urate,

\author{
Correspondence to: \\ Dr Wannamethee. \\ Accepted for publication \\ 28 May 1997 \\ Primary Care and \\ Rowland Hill Street \\ London NW3 2PF, UK \\ $S$ G Wannamethee \\ A G Shaper \\ P H Whincup
}


were made on each serum sample using a Technicon SMA $12 / 60$ autoanalyser (Technicon Instruments, Tarrytown, New York, USA) at the Wolfson Research Laboratories, Queen Elizabeth Hospital, Birmingham.

Details of blood pressure, blood lipid, and heart rate measurements ${ }^{11-13}$ and classification methods for alcohol consumption, occupation (social class), smoking habits, and physical activity have been reported. ${ }^{10}{ }^{14}$ Heavy drinking is defined as consumption of more than six drinks daily or on most days ( 1 drink $=8-10 \mathrm{~g}$ alcohol). Forced expiratory volume in one second $\left(\mathrm{FEV}_{1}\right)$ was measured with a Vitalograph spirometer (Vitalograph Medical Instrumentation, Buckingham, UK) with the subjects seated and $F E V_{1}$ measurements were height standardised to the average height of the men in the study.

\section{TRIGLYCERIDE AND SERUM INSULIN}

Triglyceride and insulin measurements were available in 18 towns $(n=5664$ and $n=$ 5649 , respectively) and were adjusted for the marked diurnal variation observed in both variables. ${ }^{15}$

PRE-EXISTING DISEASE AND DRUG TREATMENT The men were asked whether a doctor had ever told them that they had angina or myocardial infarction (heart attack, coronary thrombosis), stroke, diabetes, and several other disorders. They were also asked for details of any regular drug treatment including use of antihypertensive drugs. Only 375 men reported regular use of antihypertensive drugs. Men on diuretics who did not recall a diagnosis of hypertension or cardiovascular disease were not included in the group on antihypertensive drugs. The WHO (Rose) chest pain questionnaire ${ }^{16}$ was administered to all men at the initial examination and a three-orthogonal lead electrocardiogram was recorded at rest.

\section{Pre-existing coronary heart disease}

The men were separated into three groups according to the evidence of coronary heart disease at screening.

(1) No evidence of coronary heart disease on WHO chest pain questionnaire or electrocardiogram and no recall of a doctor diagnosis of ischaemic heart disease $(n=5757)$.

(2) Men with evidence suggesting coronary heart disease short of a definite myocardial infarction. This group contains those with electrocardiographic evidence of possible or definite myocardial ischaemia or possible myocardial infarction, those with angina or a possible myocardial infarction on WHO (Rose) chest pain questionnaire, or with recall of a doctor diagnosis of angina $(n=1508)$.

(3) Men with a previous definite myocardial infarction on electrocardiogram or who recalled a doctor diagnosis of a myocardial infarction ("heart attack") $(n=425)$.

FOLLOW UP

All men were followed up for all cause mortality and for cardiovascular morbidity. ${ }^{17}$ All car- diovascular events occurring in the period up to December 1995 are included in the study, an average follow up of 16.8 years (range 15.5-18.0 years) and follow up has been achieved for $99 \%$ of the cohort. Information on death was collected through the established "tagging" procedures provided by the National Health Service registers in Southport (England and Wales) and Edinburgh (Scotland). Non-fatal events were ascertained by direct reports from general practitioners and by regular reviews of the patients' notes. A non-fatal myocardial infarction was diagnosed according to WHO criteria, which included any report of myocardial infarction accompanied by at least two of the following: a history of severe chest pain, electrocardiographic evidence of myocardial infarction, and cardiac enzyme changes associated with myocardial infarction. Fatal coronary heart disease events were defined as deaths from coronary heart disease (ICD 9th revision, codes 410-414) as the underlying cause.

\section{STATISTICAL METHODS}

Cox proportional hazards model was used to estimate the relative risks adjusted for age, smoking, alcohol intake, body mass index, presence of diabetes, pre-existing coronary heart disease, heart rate, $\mathrm{FEV}_{1}$, and diastolic blood pressure. ${ }^{18}$ Relative risks for the five urate groups were obtained by fitting urate as four dummy variables (for the five urate groups). Tests for trend were carried out fitting urate in its original continuous form. In the adjustment, age, body mass index, cholesterol, $\mathrm{FEV}_{1}$, and diastolic blood pressure were fitted as continuous variables. Smoking (five levels: never, ex-, light, moderate, and heavy), alcohol (five levels: none, occasional, light, moderate, heavy), pre-existing coronary heart disease (three levels: none, group 1 and group 2), use of antihypertensive treatment (yes/no), and history of diabetes (yes/no) were fitted as categorical variables.

\section{Results}

During the mean follow up period of $16 \cdot 8$ years there were 1085 major coronary heart disease events (fatal and non-fatal) in the $\mathbf{7 6 8 8}$ men with available data on serum urate. The mean (SD) serum urate concentration in these 7688 men was $358 \cdot 8(69 \cdot 8) \mu \mathrm{mol} / 1$, range 91 to $995 \mu \mathrm{mol} / 1$.

\section{URATE AND CORONARY HEART DISEASE RISK} FACTORS

Urate was strongly associated with body mass index (BMI) $(r=0.29 ; \mathrm{P}<0.0001)$ but no association was seen with age.

\section{Lifestyle factors and pre-existing disease}

Table 1 shows the age and BMI adjusted mean serum urate concentrations by personal characteristics and disease status. Antihypertensive treatment and pre-existing coronary heart disease were significantly associated with higher levels of serum urate after adjustment for age and BMI. Urate levels increased 
Table 1 Mean serum urate by levels of personal characteristics and pre-existing disease. Body mass index (BMI) adjusted for age, all others adjusted for age and BMI

\begin{tabular}{|c|c|c|c|}
\hline Factors & $n$ & Adjusted mean (SE) & $\begin{array}{l}\text { Test for difference } \\
\text { between groups }\end{array}$ \\
\hline \multicolumn{4}{|l|}{$\mathrm{BMI}\left(\mathrm{kg} / \mathrm{m}^{2}\right)$} \\
\hline $\begin{array}{l}<20 \\
20-\end{array}$ & $\begin{array}{l}266 \\
698\end{array}$ & $\begin{array}{l}314 \cdot 7(4 \cdot 10) \\
326 \cdot 1(2 \cdot 53)\end{array}$ & \multirow{4}{*}{$P<0.0001$} \\
\hline $22-$ & 1537 & $343.5(1.71)$ & \\
\hline $24-$ & 2069 & $357 \cdot 2(1 \cdot 47)$ & \\
\hline $\begin{array}{l}26- \\
28-\end{array}$ & $\begin{array}{l}1629 \\
1486\end{array}$ & $\begin{array}{l}368.8(1.66) \\
389.0(1.73)\end{array}$ & \\
\hline \multicolumn{4}{|c|}{ Antihypertensive treatment } \\
\hline No & 7313 & $356 \cdot 3(0 \cdot 77)$ & \multirow[t]{2}{*}{$P<0.0001$} \\
\hline Yes & 375 & $406 \cdot 7(3 \cdot 45)$ & \\
\hline \multicolumn{4}{|c|}{ Pre-existing IHD } \\
\hline None & 5755 & $357 \cdot 0(0 \cdot 88)$ & \multirow[t]{3}{*}{$P<0.0001$} \\
\hline Grade II & 1508 & $361.9(1.72)$ & \\
\hline Def MI & 425 & $371 \cdot 7(3 \cdot 26)$ & \\
\hline \multicolumn{4}{|l|}{ Diabetes } \\
\hline No & 7571 & $359 \cdot 4(0 \cdot 77)$ & \multirow[t]{2}{*}{$P<0.0001$} \\
\hline Yes & 117 & $320 \cdot 2(6 \cdot 16)$ & \\
\hline \multicolumn{4}{|l|}{ Smoking } \\
\hline Never & 1812 & $360 \cdot 7(1.57)$ & \multirow{5}{*}{$P<0.0001$} \\
\hline Ex- & 2700 & $366 \cdot 1(1 \cdot 29)$ & \\
\hline $1-19^{\star}$ & 1176 & $354.1(1.95)$ & \\
\hline $20^{\star}$ & 833 & $348 \cdot 0(2 \cdot 31)$ & \\
\hline $21-\star$ & 1151 & $351 \cdot 2(1.97)$ & \\
\hline \multicolumn{4}{|l|}{ Alcohol } \\
\hline None & 461 & $344 \cdot 7(3.05)$ & \multirow{5}{*}{$P<0.0001$} \\
\hline Occasional & 1831 & $343.0(1.53)$ & \\
\hline Light & 2531 & $356 \cdot 8(1 \cdot 30)$ & \\
\hline Moderate & 2030 & $366 \cdot 7(1 \cdot 46)$ & \\
\hline Heavy & 829 & $387 \cdot 8(2 \cdot 28)$ & \\
\hline
\end{tabular}

IHD, ischaemic heart disease; Def MI, definite myocardial infarction.

$\star$ Cigarettes per day. glucose concentration of about $8.0 \mathrm{mmol} / \mathrm{l}$; at higher levels of glucose, serum urate decreased. ${ }^{19}$

With the exception of blood pressure, the associations with biological factors persisted even after additional adjustment for pre-existing coronary heart disease, antihypertensive treatment, diabetes, alcohol intake, and smoking. The correlations between urate and blood pressure were weakened $(r=0.04$ and $r=$ 0.02 for diastolic and systolic blood pressure, respectively) although the correlation remained significant for diastolic blood pressure. Since cholesterol and triglyceride are strongly correlated $(r=0.37)$ we examined the relation between urate and cholesterol and triglyceride adjusting in addition for each of the other factors. Triglyceride remained strongly associated with urate but the relation with cholesterol, although statistically significant, was markedly attenuated $(r=0.05)$.

\section{SERUM URATE AND RISK OF CORONARY HEART DISEASE}

In order to determine the role of confounding factors and because the biological factors such as blood lipids and blood pressure may be mediating factors, we have examined the relation between serum urate and risk of coronary heart disease by quintiles of serum urate (table 2) adjusting successively and cumulatively for potential confounding variables: (A) age only, (B) lifestyle factors, (C) disease indicators, and (D) biological factors (cholesterol and diastolic blood pressure). In this study serum triglyceride is not an independent risk factor for coronary heart disease once blood cholesterol has been taken into account, and it has therefore not been included in the adjustment. ${ }^{20} \mathrm{~A}$ strong and significant positive association was seen between urate and risk of coronary heart disease after adjustment for age (table 2; A). Further adjustment for lifestyle factors shown to be associated with uratesmoking, BMI, and alcohol-made little difference to the relation (B). Additional adjustment for disease indicators, that is, preexisting coronary heart disease, use of antihypertensive treatment, and lung function, attenuated the positive relation slightly but the trend remained significant (C). Finally, adjustment for diastolic blood pressure and blood cholesterol considerably weakened the relation (D). Although men in the lowest quintile of serum urate showed significantly lower risk than the rest, there was no difference between the other groups and a test for trend was not

Table 2 Serum urate and age adjusted coronary heart disease (CHD) rates/1000 person-years and adjusted relative risk of coronary heart disease, with $95 \%$ confidence intervals

\begin{tabular}{|c|c|c|c|c|c|c|c|}
\hline \multirow{2}{*}{$\begin{array}{l}\text { Urate } \\
\text { fifths }\end{array}$} & \multirow{2}{*}{$\begin{array}{l}n \\
1530 \\
1537 \\
1533 \\
1572 \\
1516\end{array}$} & \multicolumn{2}{|c|}{$\begin{array}{l}\text { Age adjusted } \\
\text { cases rate/1000 } \\
\text { person-years }\end{array}$} & \multirow{2}{*}{$\begin{array}{l}A \\
1.00 \\
1.30(1.07 \text { to } 1.59) \\
1.27(1.04 \text { to } 1.56) \\
1.39(1.14 \text { to } 1.69) \\
1.55(1.29 \text { to } 1.89)\end{array}$} & \multirow{2}{*}{$\begin{array}{l}B \\
1.00 \\
1.33(1.08 \text { to } 1.62) \\
1.32(1.08 \text { to } 1.63) \\
1.42(1.15 \text { to } 1.74) \\
1.58(1.30 \text { to } 1.95)\end{array}$} & \multirow{2}{*}{$\begin{array}{l}C \\
1.00 \\
1.36(1.10 \text { to } 1.66) \\
1.36(1.11 \text { to } 1.69) \\
1.42(1.15 \text { to } 1.74) \\
1.42(1.16 \text { to } 1.76)\end{array}$} & \multirow{2}{*}{$\begin{array}{l}D \\
1.00 \\
1.32(1.07 \text { to } 1.62) \\
1.28(1.04 \text { to } 1.58) \\
1.29(1.05 \text { to } 1.59) \\
1.27(1.03 \text { to } 1.57)\end{array}$} \\
\hline & & $\begin{array}{l}173 \\
214 \\
208 \\
236 \\
254\end{array}$ & $\begin{array}{r}7 \cdot 4 \\
9 \cdot 6 \\
9 \cdot 2 \\
10 \cdot 1 \\
11 \cdot 5\end{array}$ & & & & \\
\hline Test for trend & & & & $\mathrm{P}<0.0001$ & $P<0.0001$ & $P=0.007$ & $P=0.12$ \\
\hline
\end{tabular}

A, adjusted for age; B, adjusted for A, smoking, body mass index, and alcohol intake; $C$, adjusted for $A$, B, and antihypertensive treatment, pre-existing ischaemic heart disease, diabetes, and lung function; $D$, adjusted for $A, B, C$, and diastolic blood pressure and cholesterol. 
significant $(P=0 \cdot 12)$. To assess whether diastolic blood pressure or blood cholesterol in particular attenuated this relation, these two factors were entered separately in the model. Blood cholesterol emerged as the critical factor in attenuating the relation. The adjusted relative risk when only blood cholesterol was included in addition to lifestyle factors and indicators of disease was $1.00,1.34,1.30$, 1.32 , and 1.30 for the five groups, respectively. Thus additional inclusion of diastolic blood pressure had little further effect on the relation.

URATE AND RISK OF CORONARY HEART DISEASE BY EVIDENCE OF PRE-EXISTING CORONARY HEART DISEASE

Because of the strong association between serum urate and presence of coronary heart disease, we examined the relation between serum urate by grades of pre-existing coronary heart disease at baseline, adjusting first (A) for lifestyle factors and disease indicators and then (B) in addition for blood cholesterol and diastolic blood pressure (table 3 ). In men with no pre-existing disease, after adjustment for lifestyle factors and disease indicators (column A), a positive association was seen, but this was considerably attenuated after further adjustment for cholesterol and diastolic blood pressure (column B). In men with pre-existing coronary heart disease short of a definite myocardial infarction, risk was lowest in men with low urate but there was no difference between the other groups. A positive association was seen in men with pre-existing definite myocardial infarction even after adjustment for diastolic blood pressure and cholesterol and the trend was of marginal significance $(P$ $=0.07$ ).

Exclusion of men with definite myocardial infarction on antihypertensive treatment ( $\mathrm{n}=$ 92) increased the positive association seen in men in group 3 (test for trend $P=0.02$ ), with those in the top quintile showing an almost twofold increase in risk of subsequent major

Table 3 Serum urate and risk of coronary heart disease (CHD) by grades of pre-existing $C H D$ adjusted for $(A)$ age, smoking, body mass index, and alcohol intake, antihypertensive treatment, history of diabetes, lung function, and $(B)$ in addition for diastolic blood pressure and cholesterol. 7578 men with data on all covariates

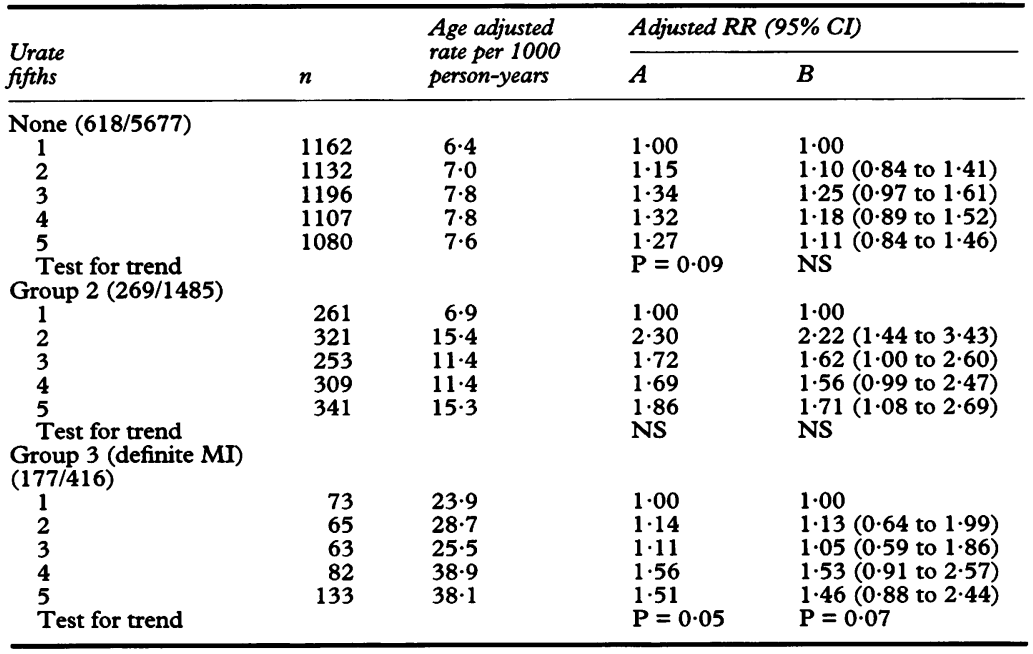

MI, myocardial infarction. coronary heart disease events compared to men in the lowest quintile after adjustment for diastolic blood pressure and cholesterol (adjusted relative risk $(R R)=1 \cdot 95 ; 95 \%$ confidence interval (CI) 1.07 to 3.56 ). This positive association was still seen even after exclusion of cases which occurred within the first five years of follow up (adjusted $R R=$ $1 \cdot 73,95 \%$ CI 0.83 to $2 \cdot 10$; test for trend $\mathrm{P}=$ 0.09 ) although the trend was not significant, possibly due to the small numbers involved (266 men; 84 cases)

SERUM URATE AND RISK SCORE FOR CORONARY HEART DISEASE IN ABSENCE OF PRE-EXISTING CORONARY HEART DISEASE

If serum urate is integrally related to many of the risk factors for major coronary heart disease events, then as overall risk of major coronary heart disease as manifest by a clustering of risk factors (risk score) increases, one would expect levels of serum urate to increase even in the absence of evidence of pre-existing coronary heart disease. In table 4, all men with pre-existing coronary heart disease (groups 2 and 3) were excluded and serum urate levels were examined in relation to progressively increasing risk of coronary heart disease as assessed by a multifactorial risk score, which includes age, smoking, systolic blood pressure, cholesterol, ECG ischaemia, ECG definite myocardial infarction, diagnosis of coronary heart disease, current angina, diabetes, and parental history of heart disease. ${ }^{21}$ Mean serum urate increased significantly with increasing risk score even in the absence of underlying coronary heart disease.

\section{ALL CAUSE MORTALITY}

There were 1510 deaths from all causes during the follow up period. The relation between serum urate and all cause mortality was examined by evidence of pre-existing coronary heart disease. No association was seen in any of the three groups after adjustment for age, lifestyle factors, disease indicators, diastolic blood pressure, and cholesterol.

RENAL FUNCTION AND RISK OF CORONARY HEART DISEASE

Serum urate was significantly correlated with serum creatinine and urea even after adjustment for age and BMI $(r=0.29$ and $r=$ $0 \cdot 13$, respectively). This correlation was seen in men with and without pre-existing coronary

Table 4 Mean serum urate (umolll) by BRHS full scoret ranked by fifth of the whole distribution. Men with preexisting ischaemic heart disease (grades II and III) were excluded after this ranking

\begin{tabular}{lll}
\hline $\begin{array}{l}\text { BRHS score } \\
\text { (fifhs) }\end{array}$ & No of men & Mean urate (SE) \\
\hline 1 & 1377 & $348 \cdot 6(1 \cdot 71)$ \\
2 & 1291 & $355.9(1.81)$ \\
3 & 1207 & $359 \cdot 2(2 \cdot 02)$ \\
4 & 1107 & $358 \cdot 2(2 \cdot 04)$ \\
5 & 636 & $362 \cdot 1(2.91)$ \\
Test for trend & & $P<0.0001$ \\
\hline
\end{tabular}

†Full score includes age, smoking, systolic blood pressure, cholesterol, ECG ischaemia, ECG definite myocardial infarction, diagnosis of ischaemic heart disease, current angina, diabetes, and parental history. 
heart disease. However, no association was seen between blood urea and risk of coronary heart disease or between creatinine and risk of coronary heart disease. In particular no association was seen between these renal factors and risk of coronary heart disease in men with definite myocardial infarction, unlike that seen with serum urate.

\section{HISTORY OF GOUT}

Serum urate concentration was significantly raised in the 197 men who recalled a doctor diagnosis of gout (age and BMI adjusted urate concentration $415.4 \quad v \quad 357.3 \mu \mathrm{mol} / 1 ; \quad \mathrm{P}<$ $0.0001)$. However, there was little association between a history of gout and subsequent risk of coronary heart disease, even after adjusting only for age (age adjusted RR $1 \cdot 19,95 \%$ CI $0 \cdot 85$ to $1 \cdot 66$ ).

\section{Discussion}

In this study of middle aged men, raised serum urate was associated with a significant increase in risk of heart attacks after adjustment for age, as has been observed in other prospective studies. However, as in several other large population studies, we found that serum urate was associated with many of the cardiovascular risk factors, in particular obesity, use of antihypertensive treatment, alcohol intake, hyperlipidaemia, and the presence of coronary heart disease. ${ }^{3-622-25}$ Although several epidemiological and clinical studies have reported a significant association between hyperuricaemia and hypertension, in our study there was only a weak association between serum urate and blood pressure (diastolic only) after adjusting for BMI and other lifestyle factors. Several population studies have also noted weak $^{67}$ or no association between uric acid and blood pressure after BMI or antihypertensive treatment is taken into account in multivariate analyses. ${ }^{24}$ The negative association between smoking and serum urate levels observed in this study has also been reported by others. ${ }^{2}$ Although raised serum urate has been shown to be associated with an increased risk of development of diabetes, ${ }^{26}{ }^{27}$ diabetics have significantly lower mean urate concentrations, a phenomenon also observed in a study of 10000 Israeli men. ${ }^{26} \mathrm{We}$ found no association between urate and HDL cholesterol after adjustment for BMI.

\section{SERUM URATE AS AN INDEPENDENT RISK}

FACTOR

Although it has become increasingly recognised that the relation between raised serum urate and risk of coronary heart disease in men is mediated through other risk factors, it is still uncertain whether the observed relation is related to hypertension or use of antihypertensive treatment, hyperlipidaemia, or the presence of established coronary heart disease. In this study, serum urate was significantly and positively associated with risk of coronary heart disease, even after adjustment for lifestyle factors and disease indicators including pre-existing coronary heart disease and use of antihypertensive treatment. However, this relation was attenuated to non-significance after further adjustment for diastolic blood pressure and blood cholesterol. While several studies have found the increased risk to be related to use of thiazide diuretics ${ }^{8}$ or preexisting coronary heart disease, ${ }^{7}$ we found the relation to be statistically independent of these factors in multivariate analyses, but the positive relation was more concentrated in men with pre-existing coronary heart disease. The Framingham study also found the relation to be independent of use of antihypertensive treatment but it was attenuated upon adjustment for other cardiovascular risk factors, including blood pressure and cholesterol. ${ }^{4}$ The NHANES study ${ }^{28}$ and the Chicago Heart Association detection project in industry ${ }^{6}$ both found the relation between uric acid and risk of coronary heart disease to be attenuated after adjustment for a range of other cardiovascular risk factors, but neither of these studies ascertained which factors were responsible for the attenuation. The increased risk of coronary heart disease observed in our total study population appeared to be largely mediated by the association between hyperuricaemia and serum cholesterol.

\section{HYPERURICAEMIA AND HYPERLIPIDAEMIA}

Hyperlipidaemia is commonly associated with hyperuricaemia. ${ }^{42930}$ In this study we observed a significant association between urate and serum triglycerides and cholesterol. Raised triglyceride is often accompanied by a rise in cholesterol and in our study the relation between raised urate and raised cholesterol appeared to be largely mediated through triglycerides. Although our findings are based on non-fasting triglyceride concentrations, the stronger association with uric acid and triglycerides than with cholesterol has also been observed in another large prospective study ${ }^{5}$ and in studies which have used fasting triglyceride concentrations. ${ }^{29}{ }^{30}$ It is not clear why hyperuricaemia is associated with a clustering of risk factors but it has been suggested that serum uric acid, together with increased small dense low density lipoprotein cholesterol particles, may be part of the insulin resistance syndrome ${ }^{31-34}$ which in turn leads to coronary heart disease. ${ }^{33}{ }^{34}$ It is therefore possible that the association between urate and coronary heart disease is largely mediated by triglyceride metabolism. ${ }^{34}$

\section{PRE-EXISTING CORONARY HEART DISEASE}

Uric acid is often raised in patients with established coronary heart disease, as seen in this study. Although no independent association was seen between serum urate and risk of coronary heart disease in the total study population, when the relation was examined separately by grades of pre-existing coronary heart disease a significant positive association was seen in men with definite myocardial infarction, even after full adjustment. This association was strengthened upon exclusion of men on antihypertensive treatment. Men in the top fifth of the distribution showed nearly a 
twofold increase risk of coronary heart disease compared to those in the bottom fifth. In men with no evidence of coronary heart disease, a weaker but positive association was seen in the age adjusted analysis, which was attenuated after adjustment. However, in these men with no evidence of pre-existing coronary heart disease, mean serum urate concentrations increased progressively, albeit moderately, as overall risk determined by a multifactorial score increased.

Few studies have examined the role of uric acid separately by presence or absence of coronary heart disease and in the two that have done so the findings have been inconsistent. In the US coronary drug project no association was seen between raised serum uric acid and risk of non-fatal myocardial infarction in men with pre-existing myocardial infarction followed up for three years. ${ }^{4}$ In a Finnish study of 3195 men, no association was seen between serum uric acid and risk of cardiovascular mortality in men without known heart disease. ${ }^{7}$ In men with known heart disease hyperuricaemia was associated with an increase in cardiovascular mortality. Although the findings were not statistically significant after adjustment for other cardiovascular risk factors including antihypertensive medication and heart enlargement, there was still a nearly twofold increase in risk of cardiovascular mortality.

\section{GOUT AND CORONARY HEART DISEASE}

It is widely accepted that gout is a risk factor for coronary heart disease, although few prospective population studies have examined this relation. In the Framingham study, based on a 32 year follow up, men with gout ( $\mathbf{n}=$ 92) experienced a $60 \%$ excess of coronary heart disease, predominantly in the form of angina pectoris. Adjustment for other atherogenic risk factors (systolic blood pressure, total cholesterol, alcohol, BMI, diabetes) did not alter the risk of coronary heart disease in men. In women $(n=19)$, in whom gout occurred infrequently, there was no significant association between gout and CHD. ${ }^{35}$ In the present study we found no increased risk of coronary heart disease in the men with recall of a diagnosis of gout $(n=187)$ despite their raised serum urate concentrations. There also appears to be no conclusive evidence that raised serum urate in hypertensive subjects, even when induced by diuretics, worsens vascular risk. ${ }^{36} 37$

\section{CONCLUSIONS}

The significant positive association observed in the total cohort between serum urate and the risk of a major coronary heart disease event persisted after adjustment for age, lifestyle factors, and disease indicators. However, after additional adjustment for total cholesterol the increased risk was attenuated to a non-significant level. Furthermore, the relation between serum urate and major coronary heart disease events was only observed, after full adjustment, in men with previous definite myocardial infarction. The findings in this study strongly suggest that the relation observed between serum urate and the risk of major coronary heart disease events depends heavily upon the increased risk in those with previous definite myocardial infarction and severe underlying atherosclerosis. It also appears that raised serum urate is an integral part of the cluster of risk factors associated with the insulin resistance syndrome, particularly obesity, raised serum triglycerides, and raised serum cholesterol.

The British Regional Heart Study is a British Heart Foundation (BHF) Research Group and receives support from Foundation (BHF) Research Group and receives support from The Stroke Association and the Department of Health. SGW is
a BHF research fellow. We thank Professor Paul Durrington for his helpful comments in the preparation of this paper.

1 Gertler MM, Garn SM, Levine SA. Serum uric acid in relation to age and physique in health and in coronary heart disease. Ann Intern Med 1951;34:1421-31.

2 Beard JT. Serum uric acid and coronary heart disease. $A m$ Heart $\mathcal{f} 1983 ; 106: 397-400$.

3 Brand FN, McGee DL, Kannel WB, Stokes J, Castelli WP. Hyperuricemia as a risk factor of coronary heart disease: the Framingham Study. Am $\mathcal{F}$ Epidemiol 1985;121:11-18.

4 The Coronary Drug Project Research Group. Serum uric acid: its association with other risk factors and with mortality in

5 Yano K, Rhoads GC, Kagan A. Epidemiology of serum uric acid among 8000 Japanese-American Men in uric acid among 8000 Japanese-A

6 Persky VW, Dyer AR, Idris Soven E, Stamler J, Shekelle RB, Schoenberger JA, et al. Uric acid: a risk factor for coronary heart disease? Circulation 1979;59:969-77.

7 Reunanen A, Takkunen, Knekt P, Aromaa A. Hyperuricaemia as a risk factor for cardiovascular mortality. Acta Med Scand (Suppl) 1982;668:49-59.

8 Yano K, Reed DM, McGee DL. Ten year incidence of coronary heart disease in the Honolulu Heart Program: relationship to biologic and lifestyle characteristics. $A m \mathcal{F}$ Epidemiol 1984;119:653-66.

9 Selby JV, Friedman GD, Quesenberry CP. Precursors of essential hypertension: pulmonary function, heart rate, uric acid, serum cholesterol levels, and other serum uric acid, serum cholesterol levels, and other

10 Shaper AG, Pocock SI, Walker M, Cohen NM, Wale CJ, Thomson AG. British Regional Heart Study: cardiovascular risk factors in middle-aged men in 24 towns. BMF cular risk factors in

11 Bruce NG, Shaper AG, Walker M, Wannamethee G. Observer bias in blood pressure studies. $\mathcal{f}$ Hyperten 1988;6:375-80.

12 Thelle DS, Shaper AG, Whitehead TP, Bullock DG, Ashby D, Patel I. Blood lipids in middle-aged British men. Br Heart $\mathcal{F}$ 1983;49:205-13.

13 Shaper AG, Wannamethee G, MacFarlane PW, Walker M. Heart rate, ischaemic heart disease and sudden cardiac death in middle-aged British men. Br Heart $f$ 1993;70: 49-55.

14 Shaper AG, Wannamethee G. Physical activity and ischaemic heart disease in middle-aged British men. $B r$ Heart $\mathcal{f} 1991 ; 66: 384-94$

15 Perry IJ, Wannamethee SG, Whincup PH, Shaper AG Walker $M$, Alberti KGMM. Serum insulin and incident coronary heart disease in middle-aged British men. $A m \mathcal{F}$ coronary heart disease in midd

16 Cook DG, Shaper AG, Macfarlane PW. Using the WHO (Rose) angina questionnaire in cardiovascular epidemio(Rose) angina questionnaire in cardiovascular

17 Walker M, Shaper AG. Follow-up of subjects in prospective studies based in general practices. $\mathcal{F} R$ Coll Gen Pract 1984;34:365-70.

18 Cox DR. Regression models and life tables. $\mathcal{F}$ Stat Soc (B) 1972;34:187-220

19 Cook DG, Shaper AG, Thelle DS, Whitehead TP. Serum uric acid, serum glucose and diabetes: relationships in a population study. Postgrad Med $\mathcal{F}$ 1986;62:1001-6.

20 Pocock SJ, Shaper AG, Phillips AN. Concentrations of high density lipoprotein cholesterol, triglycerides, and total cholesterol in ischaemic heart disease. $B M F$ 1989;298:998-1002.

21 Shaper AG, Pocock SJ, Phillips AN, Walker M. A scoring system to identify men at high risk of a heart attack. Health Trends 1987;19:37-3.

22 Klein R, Klein B, Cornoni JC, Maready J, Cassel JC, Tyroler HA. Serum uric acid: its relationship to coronary heart disease risk factors and cardiovascular disease, Evans County, Georgia. Arch Intern Med 1973;132: 401-10.

23 Iribarren C, Sharp DS, Curb JD, Yano K. High uric acid: a metabolic marker of coronary heart disease among alcohol abstainers. $₹$ Clin Epidemiol 1996;49:673-8.

24 Okada M, Takeshita M, Ueda K, Omae T, Hirota Y. Factors influencing the serum uric acid level. A study Factors influencing the serum uric acid level. A study Japan. $\mathcal{F}$ Chronic Dis 1980;33:607-12. 
25 Goldbourt U, Medallie JH, Herman JB, Neufeld HN. Serum uric acid: correlation with biochemical, anthropometric, clinical and behavioural parameters in 10,000 Israeli men. f Chronic Dis 1980;33:435-43.

26 Medalie JH, Papier C, Herman JB, Goldbourt U, Tamir S, Neufeld HN, et al. Diabetes mellitus among 10000 adult men: Israeli Study. Isr f Med Sci 1974;10:681-97.

27 Perry IJ, Wannamethee SG, Walker M, Thomson AG, Whincup PH, Shaper AG. Prospective study of risk factors for development of non-insulin dependent diabetes tors for development of non-insulin dependent diabet
in middle-aged British men. $B M F$ 1995;310:560-4.

28 Freedman DS, Williamson DF, Gunter EW, Byers T Relation of serum uric acid to mortality and ischaemic heart disease: the NHANES I epidemiologic follow-up study. Am F Epidemiol 1995;141:637-44.

29 Berkowitz D. Blood lipid and uric acid interrelationships. ЭAMA 1964;190;120-2.

30 Zalokar J, Lellough J, Claude JR, Kuntz D. Epidemiolog of serum uric acid and gout in Frenchmen. F Chron Dis
1974 27:59-75.

31 Modan M, Halkin H, Karasik A, Lusky A. Elevated serum uric acid-a facet of hyperinsulinaemia. Diabetologia 1987;30:713-8

32 Facchini F, Chen Y-D, Hollenbeck CB. Relationship between resistance to insulin-mediated glucose uptake, urinary uric acid clearance, and plasma uric acid concentration. fAMA 1991;266:3008-11.

33 Lee J, Sparrow D, Vokonas PS, Landsberg L, Weiss ST. Uric acid and coronary heart disease risk: evidence for a role of uric acid in the obesity-insulin resistance syndrome. Am $\mathcal{F}$ Epidemiol 1995;142:288-94.

34 Krentz AJ. Insulin resistance. BMf 1996;313:1385-9.

35 Abbott RD, Brand FN, Kannel WB, Castelli WP. Gout and coronary heart disease: the Framingham study. $\mathcal{J}$ Clin Epidemiol 1988;41:237-42.

36 Hypertension and uric acid [editorial]. Lancet 1981;i: $365-6$.

37 Uric acid in hypertension [editorial]. Lancet 1987;i:1124. 